\title{
Chronic myeloid leukaemia manifesting as a gynecological emergency in a young woman
}

\author{
Vishnupriya Padmanabhan, Mohamed M. Shahin, Karim Abdallah*
}

Department of Obstetrics and Gynecology, University Hospital of North Midlands, Stoke-on-Trent, United Kingdom

Received: 01 May 2017

Revised: 15 June 2017

Accepted: 17 June 2017

\author{
*Correspondence: \\ Dr. Karim Abdallah, \\ E-mail: karimhassanfathy@yahoo.com
}

Copyright: (c) the author(s), publisher and licensee Medip Academy. This is an open-access article distributed under the terms of the Creative Commons Attribution Non-Commercial License, which permits unrestricted non-commercial use, distribution, and reproduction in any medium, provided the original work is properly cited.

\begin{abstract}
Chronic Myeloid Leukaemia (CML) is a form of blood cancer that is characterized by unregulated growth of Myeloid cells within the bone marrow. Idiopathic Spontaneous Intraperitoneal Haemorrhage (ISIH) is a rare life-threatening presentation. Case report of a young woman who presented to the emergency department with evidence of intraabdominal bleeding. thought to be of gynaecological origin. No obvious source for the bleeding could be identified intra-operatively. Laboratory investigations showed evidence of Leukaemia which was confirmed on bone marrow biopsy. CML represents $8 \%$ of leukaemia in the UK. Despite being a rare presentation, ISIH should be considered as a possible differential diagnosis for those patients when presenting with evidence of acute abdomen.
\end{abstract}

Keywords: Apoplexy, ISIH, Leukaemia

\section{INTRODUCTION}

Chronic Myeloid Leukaemia (CML) is a form of blood cancer that is characterized by unregulated growth of Myeloid cells within the bone marrow. CML is associated with the translocation of a specific chromosome (Philadelphia chromosome). ${ }^{1}$ Symptoms of CML depend on the stage of the disease. If it presents itself during the chronic phase, symptoms will range from upper quadrant pain due to Hepatosplenomegaly to fever and night sweats due to increased levels of metabolism. ${ }^{2}$ On laboratory investigations, it will usually be seen as significantly elevated white blood cell (WBC) count. Less commonly, bleeding will be the presenting the symptom during the accelerated phase of CML Idiopathic Spontaneous Intraperitoneal Haemorrhage (ISIH) is a rare life-threatening presentation. $^{3}$ Ideopathic Spontaneous Intraperitoneal Haemorrhage (ISIH) is a rare lifethreatening condition where the patient experiences severe internal bleeding which is potentially life threatening. It is a fatal rare occurrence. ISIH should be considered in a patient presenting with atypical abdominal pain, nausea, vomiting and haemodynamic instability. ${ }^{4}$ The gynaecological differential diagnosis of such presentation include a ruptured ectopic pregnancy, adenexal torsion and ovarian cyst accidents.

\section{CASE REPORT}

A 39-year-old woman presented to our emergency department with severe sudden onset abdominal pain. She had no history of abdominal trauma. On examination, general abdominal tenderness and guarding were identified. She was however, haemodynamically stable. Her urine pregnancy test was negative. Her Full Blood Count (FBC) on admission revealed Leucocytosis, with a White Cell Count of $54.810^{9} / \mathrm{L}$ and Thrombocytosis with a Platelet Count of $69510^{9} / \mathrm{L}$. A bedside ultrasound scan 
suggested an intra-abdominal haematoma. An urgent CTscan revealed a massive intra-abdominal haematoma with the suggestion of a gynaecological origin. The patient was then transferred immediately to the operating theatre where she had an emergency laparoscopy to evacuate the haematoma and identify the source of bleeding. $1600 \mathrm{ml}$ of blood was evacuated. The pelvis appeared normal on inspection with no evidence of bleeding from the genital tract. Help from the general surgical colleagues was sought and on laparoscopic inspection, we were not able to identify a source for the bleeding. the patient received 2 units of blood transfusion and made a remarkable recovery. CT-angiogram conducted postoperatively revealed no active bleeding.

In view of persistently elevated WBC and platelet counts, a Multidisciplinary team consisting of gynaecologists, general surgeons and haematologists decided to go for a bone marrow biopsy under the care of the haematology team. The biopsy revealed BCR/ABL1 re-arrangement, strongly suggestive of a Philadelphia chromosome, typically associated with Chronic Myeloid leukaemia.

\section{DISCUSSION}

Chronic Myeloid Leukaemia (CML) accounts for $8 \%$ of all Leukaemia's in the UK and is more common in men than women. ${ }^{1}$ CML is a clonal myeloproliferative disorder arising from single pluripotent hemopoietic stem cell due to acquired genetic change namely BCR/ABL1 gene rearrangement, owing to balanced reciprocal translocation involving chromosomes 9 and 22. ${ }^{2}$ More than half the patients will present with splenomegaly, less commonly with thrombotic complications, either Arterial or venous. Rarely, CML will present itself in the form of ISIH. $^{5}$

ISIH, also known as Abdominal Apoplexy is defined as intra-abdominal bleeding in absence of trauma to the abdomen. ISIH was first described in literature in 1909 by Barber and it was not until 1931 that the term abdominal apoplexy came to existence by Green and Powers. $^{6}$

Almost half of the patients with CML will present with symptoms related to thrombotic events, either arterial or venous. A less commonly seen presentation is spontaneous splenic rupture which should always be considered as a differential diagnosis for those patients when they present with symptoms and signs of acute abdomen. ${ }^{7}$ The least common cause of acute abdomen in patients with CML is spontaneous intra-abdominal bleeding with no obvious cause. Those patients present with symptoms and signs of acute abdomen with or without evidence of haemodynamic compromise and imaging studies will reveal intra-abdominal blood collection. The treatment is exclusively exploratory laparoscopy/laparotomy and a source of bleeding can't by identified in those cases. ${ }^{8}$

\section{CONCLUSION}

CML represents $8 \%$ of leukaemia in the UK. Despite being a rare presentation, ISIH should be considered as a possible differential diagnosis for those patients when presenting with evidence of acute abdomen. those cases also highlight the critical role of Multi-Disciplinary Team (MDT) involvement in formulating management plans to achieve the best possible outcome for those patients.

\section{Funding: No funding sources \\ Conflict of interest: None declared \\ Ethical approval: Not required}

\section{REFERENCES}

1. Besa EC, Buehler B, Markman M, Sacher RA, Krishnan K. Chronic Myelogenous Leukemia. Medscape Reference. WebMD. Retrieved 3 January 2014.

2. Rad MN, Abdollahi O, Golshahi G, Fard RMN. Idiopathic Spontaneous Intraperitoneal Hemorrhage: A Case Report. Clin Case Rep. 2013:3-7.

3. Cawyer JC, Stone CK. Abdominal apoplexy: a case report and review. J Emerg Med. 2011;40(3):e49e52.

4. Vidhi C, Poonam S, Priya K, Raksha A. Spontaneous Hemoperitoneum in Chronic Myeloid. J Hematol. 2013;2(1):40-1.

5. Chaudhary V, Sachdeva P, Karanth P, Arora R. Spontaneous hemoperitoneum in chronic myeloid leukemia: An unusual etiology. J Hematol. 2013;2(1):40-1.

6. Provan D, Gribben JG. Chapter 7 Chronic myelogenous leukemia. In: Molecular Hematology. 3rd ed.. Singapore: Wiley-Blackwell; 2010:76.

7. Harbour LN, Koch MS, Louis TH, Fulmer JM, Guileyardo JM. Abdominal apoplexy: two unusual cases of hemoperitoneum. Proc (Bayl Univ Med Cent. 2011;25:16-9.

8. Mubushra S, Khalid M. Idiopathic Spontaneous Intraperitoneal Haemorrhage. J Coll Phys Surg Pak. 2015;25(7):536-7.

Cite this article as: Padmanabhan V, Shahin MM, Abdallah K. Chronic myeloid leukaemia manifesting as a gynecological emergency in a young woman. Int J Reprod Contracept Obstet Gynecol 2017;6:3655-6. 